\title{
Novas narrativas nos telejornais da Globo News
}

\author{
Ana Carolina Vanderlei Cavalcanti \\ Isaltina Mello Gomes²
}

\section{Resumo}

Neste trabalho, analisamos como as tecnologias digitais móveis têm influenciado as narrativas internacionais apresentadas nos telejornais do canal de notícias 24 horas GloboNews, da Rede Globo. Com o apoio teórico de Alfredo Vizeu (2016), Antonio Fausto Neto (2006; 2007; 2008), Dominique Maingueneau (2008), Ekkehard Eggs (2008), Fabiana Piccinin (2014), José Luiz Fiorin (2004) e Yvana Fechine (2008), observamos como se dá o desvelamento do mundo pelos correspondentes da emissora, com o uso de determinadas estratégias discursivas, entre elas a de autorreferencialidade, para a construção de um ethos desses profissionais. Verificamos que a experiência do fazer jornalístico tem sido incorporada à reportagem como notícia.

Palavras-chave: Tecnologias digitais móveis. Estratégias discursivas. Construção de ethos.

\section{Abstract}

In this paper, we analyze how mobile digital technologies have been influencing the international narratives presented at GloboNews (Rede Globo's 24-hour news channel) TV news programmes. With the theoretical support of Alfredo Vizeu (2016), Antonio Fausto Neto (2006; 2007; 2008), Dominique Maingueneau (2008), Ekkehard Eggs (2008), Fabiana Piccinin (2014), José Luiz Fiorin (2004) e Yvana Fechine (2008), we observe how the unveiling of the world takes place by the channel's correspondents, with the use of certain discursive strategies, among them self-referentiality, for the construction of an ethos of these professionals. We noticed that the experience of journalism has been incorporated into the reporting as the news itself.

Keywords: Mobile digital technologies. Discursive strategies. Ethos construction.

\footnotetext{
1 Doutoranda em Comunicação pela UFPE, Mestra em Comunicação pela UFPB e em Jornalismo Internacional pela City University de Londres (foi bolsista do programa Chevening do Conselho Britânico), Especialista em Relações Internacionais pela UNICAP e Bacharel em Comunicação Social com habilitação em Jornalismo também pela UFPE. Email:ana_carolinavc@yahoo.com.br.

2 Professora Titular da UFPE e atua como docente no curso de Jornalismo, do Departamento de Comunicação Social da UFPE, e no Programa de Pós-Graduação em Comunicação da UFPE. Email: isaltina@gmail.com.
}

Revista Pauta Geral-Estudos em Jornalismo, Ponta Grossa, vol. 6, n. 1, p. 59-77, Jan/Jun, 2019. 


\section{Introdução}

O contexto de convergência e mobilidade levou o telejornalismo a romper com antigos paradigmas da televisão e a buscar formas de atualização de sua linguagem tradicional, que prezava, sobretudo, por produzir relatos com efeito de objetividade acerca de fatos cotidianos e por manter determinados padrões técnicos na captação e difusão de conteúdos televisuais. Observamos que o esforço para lidar com os desafios desse cenário tem levado os telejornais da GloboNews a experimentarem novas narrativas, especialmente no contexto das notícias internacionais, sempre que tecnologias de comunicação e informação incrementam as possibilidades de cobertura, proporcionam maior facilidade no deslocamento dos correspondentes, produção de conteúdo exclusivo e participação desses profissionais nos noticiários da emissora.

Os correspondentes, profissionais que moram por um período indeterminado em outro país, e os enviados especiais, designados, pontualmente, para cobrir determinados fatos ou eventos, são os repórteres que representam, no exterior, os veículos de comunicação para os quais trabalham. Eles são os mediadores responsáveis por testemunhar e traduzir fatos e acontecimentos internacionais para o público de seus países de origem (CAVALCANTI, 2014). No caso dos telejornais, a presença de correspondentes internacionais também pode ser compreendida como uma legitimação em torno do universo de práticas cotidianas do fazer jornalístico.

Em outras palavras: manter correspondentes em 'praças' internacionais proporciona tanto um incremento no suposto contrato discursivo da emissora em traduzir de maneira mais tangível fatos ocorridos em contextos distantes de suas sedes quanto aponta para uma lógica de poder e legitimação em relação à concorrência (CAVALCANTI; SOARES, 2013, p.01).

Neste trabalho, analisamos como as tecnologias digitais móveis têm influenciado as narrativas internacionais apresentadas nos telejornais do canal de notícias 24 horas GloboNews, da Rede Globo. Percebemos que os relatos dos correspondentes da GloboNews estão cada vez mais "molhados"3 das experiências que vivem ao se

\footnotetext{
3 Tomamos como referência a ideia de que o contexto teórico do conhecimento do jornalismo é o da união dialética da teoria com a prática. Assim, na relação com os fatos, o jornalismo e os jornalistas precisariam molhar-se pela realidade, assumindo uma condição de sujeitos e, ao mesmo tempo, de objetos, envolvidos pelo real, molhados

Revista Pauta Gerall-Estudos em Jornalismo, Ponta Grossa, vol. 6, n. 1, p. 59-77, Jan/Jun, 2019.
} 
aproximarem da realidade sobre a qual precisam reportar. Com frequência, a experiência do fazer jornalístico da reportagem se mistura à própria notícia ou até mesmo ocupa seu lugar. Além disso, os apresentadores dos telejornais da emissora também recorrem, com naturalidade, a estratégias de celebração e consagração (FAUSTO NETO, 2008) desses profissionais.

Para examinarmos essas mudanças e refletirmos sobre um contexto que está em constante atualização, tomamos como referência os conceitos de função pedagógica do jornalismo, construção do ethos, autorreferencialidade e atorização. As reflexões que apresentamos aqui fazem parte de uma pesquisa de doutorado, em andamento, vinculada ao Programa de Pós-Graduação em Comunicação da Universidade Federal de Pernambuco.

\section{Contextualizar e traduzir: operações didáticas na cobertura internacional da Globo News}

Alfredo Vizeu e Laerte Cerqueira (2017) defendem que, no contexto da realidade brasileira, o jornalismo amplia sua força no telejornalismo e este produz o conhecimento do desvelamento, descortinando o saber de várias áreas e entregando fragmentos do que ocorre no mundo ao público. Nesse sentido, o telejornalismo, como espaço para construção social de representações do mundo, tem uma função pedagógica ${ }^{4}$, e esta se concretiza em três dimensões para produzir o conhecimento do cotidiano. Uma delas é a dos processos didáticos, que são operações na produção de uma notícia, que tornam o conteúdo mais compreensível para a audiência e podem ter origem tanto em ações individuais quanto em coletivas, internalizadas nas rotinas produtivas. A ambientação, a contextualização, a complementaridade, a exemplificação e a descrição em arte são algumas dessas operações (VIZEU; CERQUEIRA, 2017).

A análise dos telejornais da GloboNews revela que os correspondentes e enviados especiais da emissora recorrem a processos didáticos quando, principalmente, priorizam em seus relatos informações traduzidas e contextualizadas para a audiência, construindo pontes entre realidades diferentes a partir do que veem, ouvem e verificam

nele. Essa concepção é apresentada por Alfredo Vizeu e Adriana Santana (2010), a partir do pensamento de Paulo Freire.

${ }^{4}$ Alfredo Vizeu baseia sua reflexão sobre a função pedagógica do telejornalismo nos sete saberes da prática educativa descritos por Paulo Freire na obra Pedagogia da Autonomia.

Revista Pauta Geral-Estudos em Jornalismo, Ponta Grossa, vol. 6, n. 1, p. 59-77, Jan/Jun, 2019. 
(CAVALCANTI, 2014). Contextualizar pode ser entendido, de acordo com Vizeu e Adriana Santana (2010, p.42), como "colocar o máximo possível de peças no quebra-cabeça noticioso, contribuindo para que o fato faça parte de uma história, e não visto de forma isolada do mundo que o cerca".

Iluska Coutinho (2009, p.108) reforça que "o conhecimento social da realidade via tela de televisão" se dá por meio de uma janela particular (e não de uma janela que permite ver o mundo), uma vez que envolve desde características do meio à política editorial da emissora responsável pelo telejornal. Neste, segundo Arlindo Machado (2009), só existem mediações. O pesquisador diz que os eventos não são apresentados como simples reflexão da realidade ou como mero recurso de aproximação de algo que acontece em outra parte. Tanto enunciados de repórteres quanto de protagonistas são mediações e condição sem a qual não se dá o relato telejornalístico. E essa perspectiva reafirma o caráter de representação da realidade do telejornal (COUTINHO, 2009).

De acordo com Itania Mota Gomes (2007), a relação entre programas e telespectadores é regulada por um pacto tácito sobre o papel do jornalismo na sociedade. "É esse pacto que dirá ao telespectador o que deve esperar ver no programa" (GOMES, 2007, p.26). Nessa perspectiva, o principal pacto que a GloboNews faz com os seus assinantes é oferecer jornalismo em tempo real. Na televisão, tempo real é sinônimo de programação ao vivo, isto é, de transmissão direta, e informação instantânea. A transmissão direta, segundo Yvana Fechine (2008), é um fato técnico, que permite a produção, a transmissão e a recepção de um programa de modo simultâneo, o que, para François Jost (2004, p.18), além de produzir um efeito de atualidade, agrega "uma promessa ontológica de autenticidade" ao conteúdo apresentado.

$\mathrm{Na}$ emissora, as coberturas ao vivo de fatos nacionais e internacionais considerados relevantes têm prioridade na programação e costumam receber reforço tanto para contextualização quanto para a análise do que já aconteceu ou está em desenvolvimento. O jornalismo em tempo real e o jornalismo já tratado, decodificado, definem a emissora, segundo João Roberto Marinho (apud PATERNOSTRO, 2006), vicepresidente das Organizações Globo.

$\mathrm{Na}$ GloboNews, correspondentes e uma rede frequente de colaboradores estão presentes em cidades estratégicas nos Estados Unidos, na Europa, na Ásia e na América do Sul, de onde trazem relatos sobre acontecimentos relevantes. Os profissionais que estão em Nova lorque, nos Estados Unidos, e em Londres, na Inglaterra, contam com o Jan/Jun, 2019. 
apoio da estrutura dos escritórios da Rede Globo nesses locais. Os demais, não. Por isso, suas casas acabam servindo também como base e, inclusive, cenário para participações ao vivo na emissora. É importante registrar que as cidades são, na verdade, pontos de referência para as coberturas. A partir de Zurique, na Suíça, por exemplo, a jornalista Bianca Rothier responde também por outras áreas da Europa. $E$ isso significa dizer que ela é deslocada, como enviada especial, para estar no local dos fatos ou que, quando ela mesma não pode ser uma mediadora-testemunha dos acontecimentos narrados, a sua presença é substituída por uma construção discursiva que promove um efeito de proximidade, a partir de uma lógica de pertencimento a uma geopolítica da fonte a ser destacada no conteúdo, entre o país onde se encontra e o conteúdo (informações e imagens) produzido pelas agências de notícias (CAVALCANTI; SOARES, 2013).

A relação de dependência da emissora com as agências de produção de imagens jornalísticas para a televisão, que não só agendam os principais temas do noticiário como fornecem material para as coberturas, é clara. No entanto, na rotina produtiva dos profissionais que lidam com a realidade dos acontecimentos no mundo, seja no Brasil ou fora das fronteiras do país, esse material é quase sempre apenas ponto de partida. Correspondentes, enviados especiais e colaboradores não são os únicos pilares da cobertura internacional da GloboNews. Apresentadores, editores e comentaristas também fazem parte desse processo de desvelamento e compreensão do mundo (COUTINHO, 2009; VIZEU, 2014), cumprindo, de forma coordenada, processos didáticos da função pedagógica do jornalismo, quando traduzem, contextualizam, problematizam e aproximam a realidade do mundo da audiência brasileira.

\section{As estratégias de autorreferencialidade e atorização na construção de um ethos do correspondente internacional}

Fechine (2008) defende que a credibilidade dos telejornais é influenciada diretamente pela confiança que os espectadores depositam nos seus apresentadores. Embora, de acordo com a pesquisadora, possam ser considerados a "cara" do programa que comandam, como em outros formatos televisuais, os apresentadores de telejornais, diferentemente dos que assumem este papel em outros gêneros, "constroem sua imagem numa constante tensão entre a propalada exigência de 'objetividade' e imparcialidade da prática jornalística e a autopromoção e glamourização inerentes à televisão" (FECHINE, 2008, p.69).

Revista Pauta Geral-Estudos em Jornalismo, Ponta Grossa, vol. 6, n. 1, p. 59-77, Jan/Jun, 2019. 
[...] é possível indicar, especialmente a partir dos anos 90, uma tendência geral à personalização desses apresentadores, provocando, assim, também uma mudança na própria retórica dos telejornais. Essa nova estratégia retórica sustenta-se na ênfase dada, agora, na construção do ethos dos apresentadores por meio de procedimentos determinados preliminarmente pelas estratégias enunciativas dos telejornais (FECHINE, 2008, p.69-70).

O conceito de ethos remete "à configuração de caráter por meio do qual o orador conquista a confiança da plateia com vistas à sua persuasão" (FECHINE, 2008, p.72). Para Ekkehard Eggs (2008), é possível dizer que o ethos constitui a mais importante das três provas (logos, ethos e pathos) produzidas pelo discurso, de acordo com Aristóteles, na obra Retórica, que defendia sua contribuição para a persuasão. Nesse contexto, ele empregou o termo epieíkeia, que o pesquisador traduziu como honestidade 5 . "Diremos, portanto, que o orador que mostra em seu discurso um caráter honesto parecerá mais digno de crédito aos olhos de seu auditório" (EGGS, 2008, p. 29, grifo do autor). Dominique Maingueneau (2008, p.70) reforça: "persuade-se pelo caráter (ethos) quando o discurso é de tal natureza que torna o orador digno de fé, porque as pessoas honestas nos inspiram uma confiança maior e mais imediata".

Eggs (2008) enfatiza que a credibilidade do orador é o efeito do seu discurso. O ethos não nasce de uma atitude interior ou de um sistema de valores abstratos. Ao contrário, é resultado de escolhas competentes, deliberadas e apropriadas. Como "prova retórica é, portanto, procedural" (EGGS, 2008, p.37). José Luiz Fiorin (2004, p.120) entende que o ethos explicita-se "nas marcas da enunciação deixadas no enunciado". Portanto, corresponde a uma imagem do autor discursivo, implícito no enunciado. E, por isso, o seu modo de "dizer e parecer (aparência de ser) e influencia diretamente o fazercrer sobre aquilo que é dito" (FECHINE, 2008, p.73).

O orador observado neste trabalho não é o apresentador, mas o correspondente, principal mediador da notícia no cenário internacional. É a construção do seu ethos profissional, com as estratégias mobilizadas para o estabelecimento de sua credibilidade e dos laços de confiança com os espectadores, que analisamos. Para tanto, buscamos lastro nos conceitos de autorreferencialidade e atorização.

\footnotetext{
5 Eggs (2008) explica que o sentido de ethos, na obra de Aristóteles, assume tanto esse sentido moral como, em outras passagens, um sentido neutro.
}

Revista Pauta Geral-Estudos em Jornalismo, Ponta Grossa, vol. 6, n. 1, p. 59-77, Jan/Jun, 2019. 
A autorreferencialidade é uma prática cada vez mais comum nos meios de comunicação. Fabiana Piccinin (2014, p.86) sugere que ela é percebida em decorrência do momento de grande imersão tecnológica "experienciado contemporaneamente, que mostra a clara influência do ritmo ditado pela produção e publicação de notícias na web, repercutindo na TV e criando novas processualidades no sistema midiático". Antonio Fausto Neto (2008, p.110) explica que "no percurso da 'sociedade dos meios' para a 'sociedade midiatizada', complexos processos têm transformado o status do jornalismo e o seu 'lugar de fala'". Na primeira realidade, o campo jornalístico, através de suas práticas discursivas, representa uma espécie de "fala intermediária". Esta se configura como um "dispositivo representacional" e articulador das atividades discursivas dos outros campos. A ênfase de sua enunciação está na capacidade de produzir relatos sobre outros campos, efetuando operações de extração, nomeação, classificação, hierarquização e tematização. Nesse lugar representacional, as estratégias discursivas não deviam tornar evidentes as marcas de suas operações (FAUSTO NETO, 2008, p.110-111).

[...] sua condição de "fala intermediária" Ihe impunha, dentre outras coisas, o compromisso da objetividade. Ainda que na prática, pudessem vir a se constituir numa questão - como foi e continua sendo central para o jornalismo - as marcas do seu "ato de fala" deveriam ser apagadas, ou então, se manter opacas.

Já na sociedade midiatizada, um fenômeno operado diretamente pelas convergências tecnológicas, Fausto Neto (2008, p.112) afirma que "os processos midiáticos ampliam sua importância por meio de várias plataformas produtivas e de circulação de mensagens e sentidos". O campo midiático deixa de ser um lugar protagonista, porque as suas referências expandem-se para toda a esfera social.

Os processos de midiatização repercutem, ao mesmo tempo, sobre a própria organização do campo das mídias, dos demais campos e dos atores sociais, reestruturando os modos de conexão destas três instâncias - campos sociais, mídias e atores sociais - segundo operações junto aos âmbitos de produção e recepção de mensagens, instalando novos modos de interação social. Mas a centralidade de lógicas das mídias empresta às práticas jornalísticas um novo regime de autonomia, não mais fundada numa 'vocação representacional', mas em um novo lugar, em termos sociotécnico-simbólicos (FAUSTO NETO, 2008, p.111).

Revista Pauta Geral-Estudos em Jornalismo, Ponta Grossa, vol. 6, n. 1, p. 59-77, Jan/Jun, 2019. 
Dentro dessa realidade, o lugar de fala é estabelecido por um novo modelo de contrato $^{6}$ da mídia com o público e este visa a interação com os receptores. Então, a "opacidade enunciativa", que configurava o estatuto representacional da sociedade dos meios, é substituída por "uma postura enunciativa autorreferencial - a natureza do seu próprio lugar, passando a chamar atenção para o que diz, sobretudo para sobre as operações que faz para nomear realidades" (FAUSTO NETO, 2008, p.112-113). Neste sentido, de acordo com Piccinin (2014, p.86), a busca pela transparência dos processos "aponta para os bastidores que ganham destaque porque autenticam/garantem a veracidade dos fatos e a informalidade da linguagem na medida em que os telejornais passam a tornar as práticas produtivas também cenário do programa".

Sofia Costa Rêgo (2017, p.23) reforça que os meios de comunicação têm, cada vez mais, recorrido à autorreferencialidade "para construir a credibilidade perante o público e ao mesmo tempo atraí-lo". Ao dar visibilidade ao modo de fazer, o jornalismo busca, além de um efeito de transparência, provar a sua veracidade em todas as suas etapas. Não basta a notícia ser verdadeira, "os bastidores também precisam provar a sua legitimidade" (RÊGO, 2017, p.24), porque também são, agora, considerados parte do produto. Nesse processo, entra em cena o que a pesquisadora chama de "desmascaramento da enunciação".

Enquanto antes o jornalismo apostava na construção da credibilidade através da imparcialidade e do distanciamento, com falas em terceira pessoa, mascarando o processo de enunciação o tempo inteiro, agora, migrou-se para o outro extremo. Atualmente busca-se a autenticidade justamente através do desmascaramento da enunciação (RÊGO, 2017, p.24).

O "rosto" dos atores envolvidos no processo também ajuda a criar os vínculos necessários nesses novos contratos, estruturando a credibilidade e atualizando a noção de confiança (FAUSTO NETO, 2007). Coutinho (2009, p.120) defende que "narradas por um rosto e/ou voz reconhecidos pelo telespectador, as estórias cotidianamente retratadas a cada edição dos telejornais ganham valor de verdade, de conhecimento válido, e legitimado por seu público".

6 O conceito "contrato de leitura" foi desenvolvido por Eliseo Verón (2004). Fausto Neto (2007) chama de contrato entre mídia e público ou de contrato de leitura as operações construídas que visam estabelecer o "modo de dizer" de um veículo de comunicação e que se explicitam nas mensagens endereçadas ao público, instituindo vínculos veículopúblico e criando, também, espaços interacionais.

Revista Pauta Geral-Estudos em Jornalismo, Ponta Grossa, vol. 6, n. 1, p. 59-77, Jan/Jun, 2019. 
Este novo esforço pedagógico com que a enunciação jornalística se estrutura, necessita explicitar o rosto do seu processo, para não dizer dos seus atores. Tece o processo de produção/recepção, através de uma 'economia do contato' no qual se instala a ligação da confiança, através de operações que o lugar da produção faz para, além de validar o seu trabalho de enunciação, oferecer as bases e referências simbólicas sobre as quais se fundará a crença (FAUSTO NETO, 2006, p.12-13).

As operações enunciativas autorreferentes parecem reforçadas na cobertura de notícias internacionais (embora não exclusivamente nessa realidade) pelos dispositivos tecnológicos disponíveis no atual contexto de convergência e mobilidade e, ainda, pelo protagonismo que naturalmente se espera de correspondentes internacionais. Carlos Eduardo Lins da Silva (2011) diz que o trabalho é visto como um prêmio e também é considerado equivalente a uma promoção dentro da carreira de repórter (UTZERI apud AGNEZ, 2012). Nessa perspectiva mais tradicional, os correspondentes costumam ser jornalistas maduros, com prestígio junto a seus pares e reconhecidos pelo público, que se destacaram em coberturas nacionais para, então, serem designados para postos no exterior. Esse é um perfil quase em extinção em muitos países e veículos, inclusive na GloboNews, que tem apostado em competências já adquiridas por jovens jornalistas: experiência relevante (independente da idade do profissional e do número de anos na reportagem), vivência em outras culturas, familiaridade com as novas tecnologias e disposição até mesmo para acumular funções. Muitos dos que fazem parte da rede de correspondentes e colaboradores da emissora no exterior já moravam fora do Brasil quando assumiram a função. Diante dessas mudanças, ainda assim, percebemos na figura do correspondente um repórter com mais autonomia para tomar certas decisões, pois muitas vezes trabalha sozinho e pode se encontrar em situações em que não é possível negociar com a redação sobre o melhor a fazer.

$\mathrm{Na}$ GloboNews, é possível constatar o que Fausto Neto (2006) chama de atorização do profissional em reportagens gravadas e em entradas ao vivo de correspondentes dentro dos telejornais da emissora, mas também ao longo dos intervalos comerciais de sua programação. A partir dessa estratégia, a confiança do público passa a se estabelecer, de acordo com o pesquisador, mais na performance jornalística do que necessariamente no que o discurso revela. No processo de construção jornalística da realidade, dentro dessa lógica, valoriza-se, segundo o pesquisador, as qualidades morais,

Revista Pauta Geral-Estudos em Jornalismo, Ponta Grossa, vol. 6, n. 1, p. 59-77, Jan/Jun, 2019. 
humanas e profissionais do repórter a serviço da matéria, e destaca-se a sua sensibilidade.

\begin{abstract}
Tais padrões de confiança passam também pelos próprios perfis dos jornalistas. São transformados em atores, celebridades, moeda de atribuição à credibilidade ao trabalho feito por eles. Não basta exaltar as virtudes dos talentos, mas dar-Ihes um modo de existência na rotina produtiva, explicitando os seus fazeres, suas competências (FAUSTO NETO, 2006, p.10).
\end{abstract}

Na sequência, apresentamos e analisamos dois exemplos extraídos de telejornais da GloboNews em que essas estratégias - de estruturação da credibilidade e de construção dos vínculos de confiança por meio da autorreferencialidade e da atorização dos jornalistas - se manifestam em contextos comunicativos de improvisação e/ou de incorporação. Entendemos improvisação como uma apropriação pontual de um dispositivo tecnológico em decorrência de circunstâncias adversas, em que se percebe a iniciativa do correspondente para assegurar a cobertura e o valor-notícia do fato reportado. Quando a apropriação está fora desse contexto de urgência e já ultrapassou a fase de experimentação ou aposta, consideramos que se trata de um uso de rotina e, portanto, de uma incorporação.

\title{
A experiência da reportagem como notícia no relato de correspondentes e enviados especiais
}

O telespectador assistiu no dia 16 de setembro de 2016 à cobertura de um dos momentos dos mais críticos da crise migratória na Europa. Naquele dia, nos telejornais da GloboNews, a mediação foi da enviada especial Bianca Rothier, já citada neste trabalho, e de um repórter cinematográfico. Eles acompanhavam as tensões provocadas pelo fechamento dos 175 quilômetros da fronteira entre a Hungria e a Sérvia pelo governo húngaro, bem como a reação de centenas de migrantes de várias nacionalidades e refugiados vindos da Síria, que, pegos de surpresa, esperavam permissão para atravessar o país a pé. Ao longo daquele dia, os enviados especiais produziram reportagens com equipamentos profissionais e também participaram ao vivo dos telejornais da emissora, usando um software ${ }^{7}$ que permite chamadas de voz e vídeo via internet, a partir de um telefone celular.

\footnotetext{
7 O software em questão foi o Skype. As marcas do programa foram evidenciadas na transmissão.
}

Revista Pauta Geral-Estudos em Jornalismo, Ponta Grossa, vol. 6, n. 1, p. 59-77, Jan/Jun, 2019. 
Bianca Rothier falava ao vivo para a edição das $10 \mathrm{~h}$ do Jornal GloboNews, improvisando via internet de um telefone celular, quando começou um confronto entre as forças de segurança e o grupo que tentava continuar sua jornada rumo ao norte da Europa. Mesmo quando a qualidade da conexão impossibilitava a compreensão do que era mostrado, as imagens foram mantidas no ar (fig. 01). A correspondente tossia em consequência do gás lacrimogêneo dispersado pela polícia húngara, não conseguia completar frases. Posteriormente, o material não editado dessa cobertura ao vivo foi reprisado diversas vezes nos telejornais daquele dia da GloboNews.

Figura 01: A correspondente, ainda acompanhada de um repórter cinematográfico, atualiza os telejornais da GloboNews ao vivo, com a internet do telefone celular

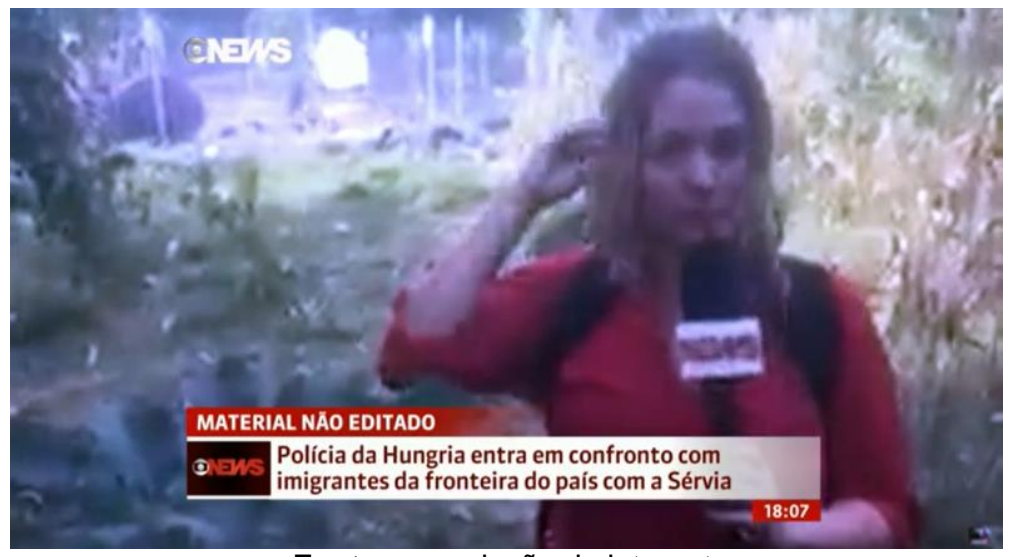

Fonte: reprodução da internet.

No meio do tumulto que acompanhava, a correspondente se perdeu do seu repórter cinematográfico e, também, perdeu contato com a emissora. Sozinha, ela passou a registrar depoimentos sobre o que via a sua volta com a câmera do seu celular (fig.02). Nesse material, que foi exibido posteriormente nos telejornais, Bianca Rothier aparece ofegante e assustada no vídeo, conforme transcrição abaixo.

Eu tou... é... (ofegante, voz trêmula) gravando aqui, agora, com o celular, eu tou sentada no chão, é... (ofegante)... muito gás lacrimogêneo. Eu me perdi do cinegrafista. Eu não... (ofegante)... é muito complicada a situação. A gente vê, agora, barulho de ambulância passando ali atrás ${ }^{8}$.

\footnotetext{
8 Transcrição de trecho não editado da cobertura realizada pela correspondente Bianca Rothier no dia 16 de setembro de 2016 nos telejornais da GloboNews.
}

Revista Pauta Gerall-Estudos em Jornalismo, Ponta Grossa, vol. 6, n. 1, p. 59-77, Jan/Jun, 2019. 
Figura 02: Perdida do repórter cinematográfico, a correspondente passa a gravar relatos sozinha, com a câmera do telefone celular

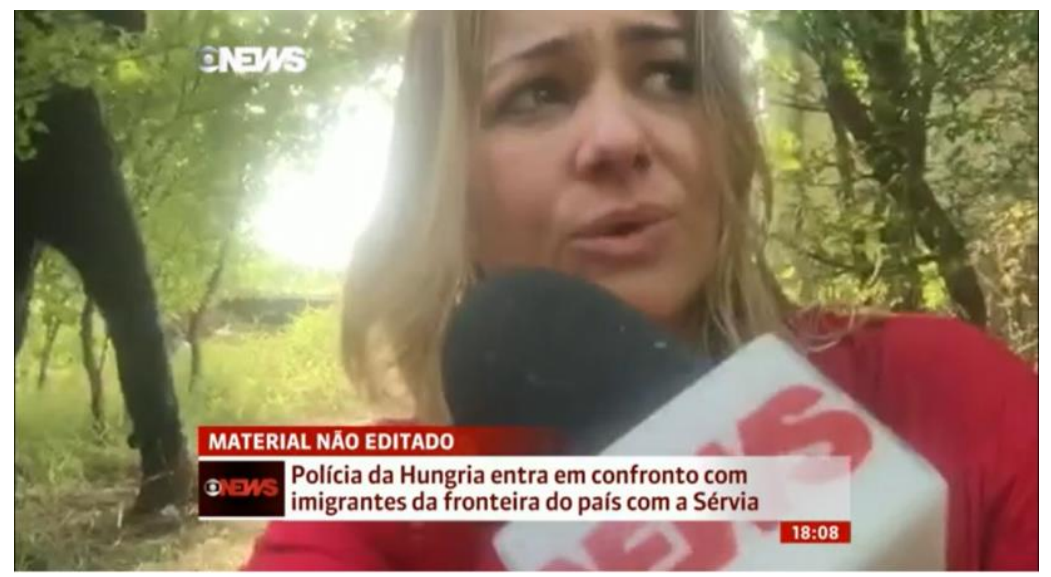

Fonte: reprodução da internet.

Na edição do Meio-Dia, os apresentadores Luciano Cabral e Heloísa Gomyde seguiram falando sobre a cobertura e enfatizaram o fato de a enviada estar no local, mostrando a situação dos migrantes e refugiados naquele contexto e passando pelas "mesmas dificuldades", por causa de jatos de água e de gás lacrimogêneo disparados pelas forças de segurança húngaras, para contar o que acontecia. Eles explicaram que haviam conseguido restabelecer o contato com Bianca Rothier, que ela estava bem, mas que havia precisado sair daquela área onde acontecia o confronto para se proteger. Eles justificaram a exibição do material não editado no ar como uma prova de que a repórter não tinha, de fato, como continuar ali.

$\mathrm{Na}$ edição das $18 \mathrm{~h}$ do Jornal GloboNews, a apresentadora Leilane Neubarth entrevistou Bianca Rothier ao vivo. A correspondente teve a oportunidade de relatar como o trabalho foi feito e de justificar a baixa qualidade técnica das imagens de parte da cobertura. Leilane Neubarth usou do mesmo expediente de Luciano Cabral e Heloísa Gomyde. Ela tratou o modo de fazer da reportagem como parte da notícia e priorizou a experiência pessoal de Bianca Rothier, questionando, ao vivo, do que a correspondente mais tinha sentido medo durante o confronto.

No dia 26 de outubro de 2017, Raquel Krähenbül participou, ao vivo, da edição das $16 \mathrm{~h}$ do Jornal GloboNews, apresentado por Cristiane Pelajo. Ela é a correspondente da GloboNews na capital dos Estados Unidos, Washington D.C., onde cobre a Casa Branca, sede do governo norte-americano. Ao longo de 1 minuto e 40 segundos, a notícia foi a 


\section{ESTUDOS EM JORNALISMO}

10.5212/RevistaPautaGeral.v6.i1.0004

liberação da credencial para que a correspondente tivesse acesso livre à Casa Branca, a primeira jornalista brasileira, segundo a emissora, a conseguir esse feito ${ }^{9}$. No vídeo, marcas do software usado para a conexão via internet do telefone celular, já incorporado à sua rotina de trabalho. O áudio estava baixo e o relato ocorreu em tom informal. Raquel Krähenbül parecia eufórica com a novidade. Gesticulou muito a mão que segurava o microfone, aproximou-se da câmera para mostrar a credencial (fig.03), girou o tripé para mostrar onde estava o Oval Office, o escritório do presidente norte-americano (fig.04), e foi parabenizada, mais de uma vez, pela apresentadora Cristiano Pelajo. A transcrição dessa participação via internet do telefone celular pode ser lida abaixo.

Cristiane Pelajo: "Notícia boa aí da Casa Branca, Raquel?"

Raquel: "Uma notícia boa pra gente da GloboNews, Cris. Hoje, finalmente, depois de muita espera aqui, nós da GloboNews conseguimos, olha (aproxima a credencial da câmera), acesso livre aqui à Casa Branca. Isso quer dizer que, agora, a gente pode entrar aqui e sair a hora que quiser, de manhã, à noite, podemos passar a madrugada de plantão aqui, no West Wing. Eu vou mostrar pra vocês (movimenta o tripé em direção ao West Wing, um contraluz invade o vídeo, o áudio fica mais baixo, e a repórter gesticula sem parar com a mão que segura o microfone). É onde ficam os escritórios, os principais escritórios, O Oval Office, o escritório do presidente dos Estados Unidos, também os dos principais assessores, aqui da Casa Branca, os porta-vozes. Então, eu posso ir a qualquer momento, agora, ali na porta dos porta-vozes, da Sarah Sanders ${ }^{10}$, por exemplo, e fazer qualquer pergunta que eu quiser, eu vou poder atormentar ela bastante agora, para trazer as informações de primeira mão para a GloboNews. E, Cris, só pra dar uma ideia de como foi difícil conseguir isso, foram meses, né, de espera? Uma checagem, pelo Serviço Secreto, muito rigorosa. Hoje, na entrevista, aqui, eles tiraram fotos para reconhecimento facial, com o FBI. Tudo vai ser mandado para a Polícia Federal Americana. Impressões digitais e, agora, nós estamos numa lista que nem todos os funcionários da Casa Branca estão. Apenas aqueles que têm acesso mais próximo do Presidente dos Estados Unidos da América, Cris. Então, vai ser muito mais fácil, agora, para contar as histórias direto daqui, da Casa Branca, para todo mundo aí no Brasil, Cris".

Cristiane: "Que legal, Raquel. Que vitória. Parabéns!

Raquel: "Obrigada!"

Cris: "Eu achava que você já tinha livre acesso a tudo, porque você já trazia várias informações aqui pra gente. Agora, então, segura a Raquel Krähenbül! Obrigada, viu? Bom trabalho pra você!"

\footnotetext{
$9 \quad$ Disponível em: http://gl.globo.com/globo-news/jornal-globonews/videos/v/correspondente-da-globonews-e-unica-brasileira-com-acesso-livre-nacasa-branca/6246068/. Acesso em: 03/04/2018.

10 Sarah Sanders é a Secretária de Imprensa do governo de Donald Trump.
}

Revista Pauta Gerall-Estudos em Jornalismo, Ponta Grossa, vol. 6, n. 1, p. 59-77, Jan/Jun, 2019. 


\section{Raquel: "Obrigada!"11}

Figura 03: Correspondente aproxima credencial da câmera para mostrá-la aos assinantes que acompanhavam a edição da $16 \mathrm{~h}$ do Jornal GloboNews

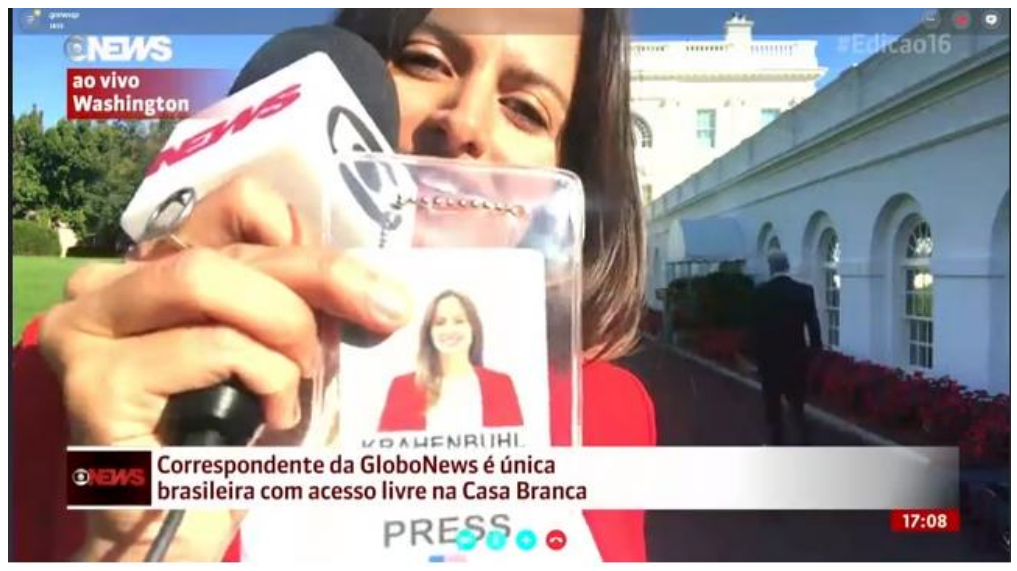

Fonte: Reprodução da internet.

Figura 04: Raquel Krähenbül passa o microfone para a mão esquerda e com a direita gira o tripé que sustenta o telefone celular em direção à área onde fica o Oval Office

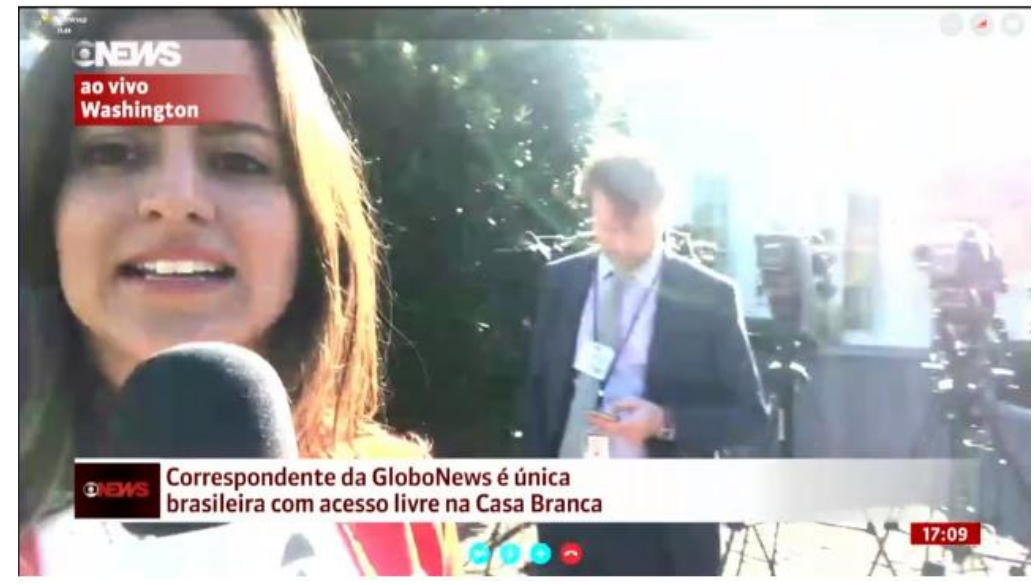

Fonte: Reprodução da internet.

$\mathrm{Na}$ conversa entre apresentadora e correspondente, foram ressaltados a dificuldade para conseguir a credencial e o mérito em consegui-la, o seu conhecimento em relação à estrutura de funcionamento da Casa Branca e a sua eficiência como correspondente naquele espaço relevante para a política mundial. Para Fausto Neto

11 Transcrição da participação ao vivo da correspondente Raquel Krähenbül no Jornal GloboNews, Edição das 16 horas, no dia 26 de outubro de 2017.

Revista Pauta Geral-Estudos em Jornalismo, Ponta Grossa, vol. 6, n. 1, p. 59-77, Jan/Jun, 2019. 
(2008, p.114), esse tipo de referência aos profissionais envolvidos no fazer jornalístico, com destaque para suas competências e performances, é também uma estratégia de celebração e consagração, pois, como ação simbólica, "visa um dizer sobre a 'epopeia' dos seus atores, segundo a qual o campo não só faz história, mas chama atenção para como esta história se faz".

Em 2017, a emissora apresentou a rotina da jornalista na sua grade de programação e também nas suas redes sociais dentro do quadro "Vida de Repórter". Raquel Krähenbül aparece em pelo menos três episódios. Neles, fala, a partir de uma perspectiva de bastidores, sobre a imprevisibilidade das pautas na Casa Branca, o trabalho ao lado de correspondentes do mundo inteiro e, ainda, sobre o que ela chamou de kit-vivo GloboNews (fig. 05). Com esse kit, formado por um telefone celular, um tripé e um microfone direcional com a canopla de identificação da emissora, a jornalista conta, em um dos vídeos, que trabalha em um esquema três em um: "a gente produz, apura e monta"12.

Embora a GloboNews não atribua um nome diferente ao que faz a correspondente na capital dos Estados Unidos, entendemos que Raquel Krähenbül, que incorporou a câmera do telefone celular em sua rotina, acumula funções e é quase sempre uma videorrepórter, porque não costuma trabalhar acompanhada de um repórter cinematográfico nem conta com apoio de uma produção local. A jornalista assume a responsabilidade por produzir, apurar, captar imagens e fazer entradas ao vivo nos telejornais da emissora.

Figura 05: Raquel Krähenbül em uma participação ao vivo na GloboNews, registrada no quadro "Vida de Repórter" com o seu kit-vivo

12 Disponível em: https://www.youtube.com/watch?v=UkJ-4F6ApEg. Acesso em: 02/03/2018.

Revista Pauta Geral-Estudos em Jornalismo, Ponta Grossa, vol. 6, n. 1, p. 59-77, Jan/Jun, 2019. 


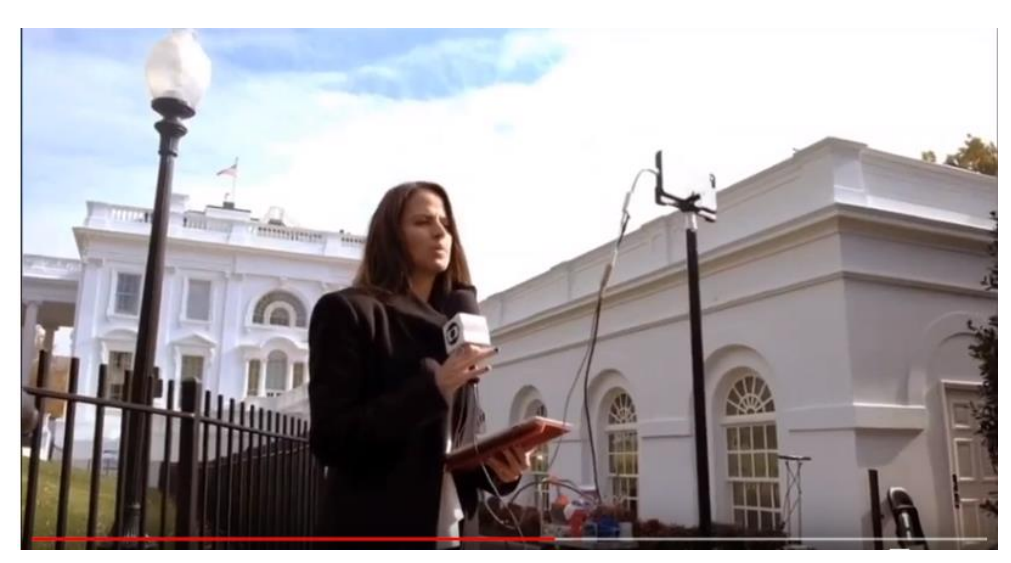

Fonte: Reprodução da internet.

Karina de Araújo Silva (2010) diz que agilidade e multifuncionalidade são características inerentes ao videorrepórter. Representam, ainda, possibilidades de mudanças para a linguagem do telejornalismo, independente do dispositivo portátil usado para gravação, como, por exemplo, "câmera e atuação subjetivas, participação e intervenção do repórter nos acontecimentos, opinião e narrações na primeira pessoa do singular" (SILVA, 2010, p.10). Todas elas, mudanças que notamos e destacamos na análise da atuação de Raquel Krähenbül como correspondente na Casa Branca e que também percebemos no material de Bianca Rothier, especialmente quando a enviada especial à Hungria passa a gravar sozinha, sem o repórter cinematográfico que a acompanhava.

\section{Algumas considerações}

A partir dos exemplos relatados aqui, em que as correspondentes trabalham em parceria com um repórter cinematográfico ou sozinhas, improvisando ou incorporando a câmera do telefone celular como dispositivo de gravação e transmissão ao vivo, percebemos que as operações enunciativas autorreferentes no desvelar o mundo foram assumidas tanto pelas profissionais em campo quanto pelos apresentadores dos telejornais da GloboNews em estúdio.

Há, nessas coberturas, um compartilhamento das experiências do fazer jornalístico da reportagem, seja ela gravada ou não, um foco na pessoa que faz o relato, que é celebrada por sua coragem ou por sua competência, e também na sua subjetividade. Além disso, há uma explicitação e uma valorização dos processos didáticos no explicar, 
contextualizar e traduzir o que acontece - desejável para o trabalho do correspondente ou enviado especial - ou o como se faz, mas que, eventualmente, é reforçado também pelo tipo de dispositivo de captação usado na cobertura.

No caso de Bianca Rothier, os sacrifícios empreendidos por ela para ser testemunha dos fatos e garantir relatos molhados de experiência ajudam a construir a autenticidade da reportagem, revelam a sua coragem pessoal e a credenciam como uma correspondente que merece não apenas a admiração, mas a confiança dos espectadores da emissora.

Com relação à Raquel Krähenbül, os enunciados autorreferentes enaltecem a sua competência e validam a sua familiaridade com aquele espaço de poder. A correspondente é celebrada e valorizada por fazer o trabalho que naturalmente se espera dela naquela função. Nas duas situações, a opção pela câmera do celular atualiza os padrões de linguagem técnica do telejornalismo (enquadramento, luz, qualidade do áudio etc.), bem como as performances das profissionais. Há mais informalidade no texto verbal, nas expressões faciais e corporais, e até mesmo no controle da respiração.

Enfim, apesar de neste trabalho o corpus ter sido reduzido, verificamos que nos telejornais da GloboNews as tecnologias digitais móveis tendem a influenciar novas narrativas sobre o mundo, incorporando a experiência do fazer jornalístico à reportagem como notícia.

\section{Referências}

AGNEZ, Luciane Fassarella. A Profissão de Correspondente Internacional: Entre Ameaças e Oportunidades. In: Anais do 10 Encontro Nacional de Pesquisadores em Jornalismo. Curitiba, 2012.

Brasil. Presidência da República. Secretaria Especial de Comunicação Social. Pesquisa brasileira de mídia 2016: hábitos de consumo de mídia pela população brasileira. Brasília: Secom, 2016.

CAVALCANTI, A. Carolina V. A cobertura internacional do Jornal Nacional: correspondentes, enviados especiais e usos de tecnologias. Florianópolis: Insular, 2014.

; SOARES, Thiago. A cobertura internacional do Jornal Nacional: Efeitos de proximidade e os fatos "a partir de uma perspectiva brasileira". In: Anais do $36^{\circ}$ Congresso Brasileiro de Ciências da Comunicação - Manaus, 2013. 
COUTINHO, Iluska. Lógicas de produção do real no telejornal: a incorporação do público como legitimador do conhecimento oferecido nos telenoticiários. In: Televisão e Realidade. Org. Itania Maria Mota Gomes. Salvador: Edufba, 2009.

EGGS, Ekkehard. Ethos aristotélico, convicção e pragmática moderna. In: Imagens de si no discurso: a construção do ethos. Ruth Amossy (org.), 1a reimpressão. São Paulo: Contexto, 2008.

FAUSTO NETO, Antonio. Notas sobre as estratégias de celebração e consagração do jornalismo. Estudos em Jornalismo e Mídia, Ano V - n. 1, pp. 109-121, jan./jun. 2008.

Contratos de Leitura: entre regulações e deslocamentos. In: Anais do XXXX Congresso Brasileiro de Ciência da Comunicação. Santos, 2007.

Mutações nos Discursos Jornalísticos: Da construção da realidade a realidade da construção. Anais do XXIX Congresso Brasileiro de Ciência da Comunicação. Brasília, 2006.

FECHINE, Yvana. Televisão e Presença. São Paulo: Estação das Letras e Cores, 2008.

Performance dos apresentadores dos telejornais: a construção do ethos. Revista Famecos, Porto Alegre, v. 1, № 36, p.69-76, jul. 2008.

FIORIN, José Luiz. O Éthos do enunciador. In: Razões e sensibilidades: a semiótica em foco. Arnaldo Cortina e Renata Coelho Marchezan (orgs.). Araraquara: Laboratório Editorial FLC/UNESP/Cultura Acadêmica Editora, 2004.

GOMES, Itania Maria Mota. Questões de método na análise do telejornalismo: premissas, conceitos, operadores de análise. Encontro do Centre d'Etudes des Images et des Sons Médiatiques/CEISME, Université Sorbonne-Nouvelle, em 5 de abril de 2007. Revista da Associação Nacional dos Programas de Pós-Graduação em Comunicação, Compós.

JOST, François. Seis lições sobre televisão. Porto Alegre: Sulina, 2004.

MACHADO, Arlindo. A televisão levada a sério. São Paulo: Editora Senac, 2009.

MAINGUENEAU, Dominique. Ethos, cenografia e incorporação. In: Imagens de si no discurso: a construção do ethos. Ruth Amossy (org.), $1^{a}$ reimpressão. São Paulo: Contexto, 2008.

PATERNOSTRO, Vera Íris (org). Globo News: 10 anos, 24 horas no ar. São Paulo: Editora Globo, 2006.

PICCININ, Fabiana. Telejornalismo, narrativa e midiatização. In: Telejornalismo em questão. Alfredo Vizeu, Edna Mello, Flávio Porcello e lluska Coutinho (Orgs.).

Florianópolis: Insular, 2014.

PORCELLO, Flávio A. C. TV e poder: as relações sombrias que ajudam a fazer a história recente do Brasil. In: Telejornalismo: a nova praça pública. Alfredo Eurico Vizeu, Célia

Revista Pauta Gerall-Estudos em Jornalismo, Ponta Grossa, vol. 6, n. 1, p. 59-77, Jan/Jun, 2019. 
Ladeira Mota e Flávio Antônio Camargo Porcello (organizadores). Florianópolis: Insular, 2006.

RÊGO, Sofia Costa. Estratégias transmídias e construção do ethos do Jornal da Record News. Dissertação (Mestrado). Universidade Federal de Pernambuco, Centro de Artes e Comunicação. Comunicação, 2017.

SILVA, Carlos Eduardo Lins da. Correspondente Internacional. São Paulo: Contexto, 2011.

SILVA, Karina de Araújo. Videorreportagem em três estilos: análise de um subgênero em formação. Dissertação (Mestrado) - Universidade Federal da Bahia, Programa de Pós-Graduação em Comunicação e Cultura Contemporâneas, 2010.

VERÓN, Eliseo. Fragmentos de um tecido. São Leopoldo: UNISINOS, 2004.

VIZEU, Alfredo; CERQUEIRA, Laerte. Saberes da pedagogia no Telejornalismo: Paulo Freire e a prática jornalística. Encontro Nacional de Pesquisadores em Jornalismo SBPJOR, São Paulo - SP, 2017.

. Jornalismo e Paulo Freire: o conhecimento do desvelamento. Revista Famecos, Porto Alegre, v. 21, n. 3, p. 860-877, setembro-dezembro 2014.

; SANTANA, A. O lugar de Referência e o Rigor do Método no Jornalismo: algumas considerações. Intexto, Porto Alegre: UFRGS, v. 1, n. 22, p. 38- 48, janeiro/junho 2010.

O telejornalismo como lugar de referência e a função pedagógica. Revista

Famecos, Porto Alegre, № 40, dezembro de 2009, quadrimestral.

Recebido em: 27/01/2019.

Publicado em: 23/07/2019.

Revista Pauta Geral-Estudos em Jornalismo, Ponta Grossa, vol. 6, n. 1, p. 59-77, Jan/Jun, 2019. 